\title{
Trend and Development of Semisolid Metal Joining Processing
}

\author{
M. N. Mohammed, ${ }^{1}$ M. Z. Omar, ${ }^{2}$ Z. Sajuri, ${ }^{2}$ M. S. Salleh, ${ }^{2}$ and K. S. Alhawari ${ }^{2}$ \\ ${ }^{1}$ Department of Engineering \& Technology, Faculty of Information Sciences and Engineering, Management \& Science University, \\ 40100 Shah Alam, Selangor, Malaysia \\ ${ }^{2}$ Department of Mechanical and Materials Engineering, Faculty of Engineering and Built Environment, \\ Universiti Kebangsaan Malaysia, 43600 Bangi, Selangor, Malaysia \\ Correspondence should be addressed to M. Z. Omar; zaidi@eng.ukm.my
}

Received 18 February 2015; Revised 4 April 2015; Accepted 4 April 2015

Academic Editor: Jainagesh A. Sekhar

Copyright $\odot 2015$ M. N. Mohammed et al. This is an open access article distributed under the Creative Commons Attribution License, which permits unrestricted use, distribution, and reproduction in any medium, provided the original work is properly cited.

The semisolid metal joining (SSMJ) process or thixojoining process has recently been developed based on the principles of SSM processing, which is a technology that involves the formation of metal alloys between solidus and liquidus temperatures. Thixojoining has many potential benefits, which has encouraged researchers to carry out feasibility studies on various materials that could be utilized in this process and which could transform the production of metal components. This paper reviews the findings in the literature to date in this evolving field, specifically, the experimental details, technology considerations for industrialization, and advantages and disadvantages of the various types of SSMJ methods that have been proposed. It also presents details of the range of materials that have been joined by using the SSMJ process. Furthermore, it highlights the huge potential of this process and future directions for further research.

\section{Introduction}

The rigid perpetual joining of materials is one of the main activities in the manufacturing and assembly process. Fusion welding is one of the most commonly used conventional joining techniques. Unfortunately, fusion welding is characterized by high temperature gradients that lead to high thermal stress and rapid solidification, which gives rise to the occurrence of segregation phenomenon. Also, the morphology of the welded interface is typically dendritic and the natural progression of solidification frequently leads to internal structural defects, such as shrinkage porosities and loss of alloying elements, resulting in a nonhomogenous microstructure [1]. Therefore, an innovative route that can avoid the abovementioned problems inherent in fusion welding is desirable. One solution that has good potential is thixojoining, which is free from the above problems because it is a semisolid state process where the solidification and heat transfer processes largely differ from those of typical welding methods.

Following the work of Spencer et al. (1972), which identified the essential thixotropic properties [2, 3], many different semisolid metal (SSM) processing or thixoforming techniques were developed to utilize the characteristic advantages of these properties $[4,5]$. This then led to other joining processes and techniques being developed called "semisolid metal joining (SSMJ)" or "thixojoining" based on the principles of SSM processing, which takes place when the material is between solidus and liquidus temperatures, that is, when the material shows thixotropic behavior $[6,7]$. Metals in a thixotropic state have many useful properties that allow them to be joined more easily, such as (1) moderate softness, (2) excellent workability, (3) good flowability, (4) flexible geometrical adaptability, and (5) active chemical and metallurgical join ability. As a result, it is easy to embed items into metals processed in this way, many kinds of solid materials can be used, and joining conditions are relatively good [5].

However, one of the most important and useful characteristics of semisolid alloys is their so-called "joinability." As is well known, semisolid alloys consist of solid and liquid components. The liquid component is usually very active during diffusion compared with the solid component and because of the active diffusion effect of the liquid component, semisolid alloys have very good joinability with other metallic and nonmetallic materials $[8,9]$. Hence, the SSMJ process has the 
potential to transform the production of metal components. Earlier research work in the 1990s has already demonstrated the feasibility of the process, but it also revealed several technical problems that need to be overcome [10]. However, thus far, researchers have not focused their attention on this particular area of work, so the technology is still in a fairly nascent stage. Therefore, fundamental investigations need to be carried out to obtain additional information about the general characteristics of this technology. The aim of this paper is to provide an overview of these investigations and the current state of research as well to discuss the possible future development activities of the thixojoining process.

\section{Technologies for SSMJ Processing}

During the last 30 years, a number of process variants have been developed under the heading SSMJ. Several authors have shown that the thixojoining process has the potential to be used for a wide range of processes that are either already patented or under investigation within research and development centres worldwide. In spite of some technical and technological differences between the available semisolid joining processes, they can be categorized into the following types: (1) addition of functional features, (2) joining metals by using semisolid slurries, (3) semisolid stir joining, and (4) semisolid diffusion joining, which are discussed below.

2.1. Addition of Functional Features. Thixojoining has many potential benefits, which has encouraged researchers to carry out feasibility studies on various materials that could be utilized in this process. The process of thixojoining has been shown to increase the functionality and complexity of components by allowing the inclusion of additional inserts in the semisolid matrix during forming. One special approach that takes advantage of the material's high flowability is the addition of functional features to a forged part. At present, there are three possible ways to obtain this additional functionality: (1) special contours, such as a screw thread, that can be thixoforged [11]; (2) functional components that can be added by joining them to a material when it is heated to the semisolid state, for example, placing steel pins into an aluminium bulk [12] (but thus far such studies have been restricted to aluminium alloys and brass); and (3) adding additional functionality by combining the forming and joining processes in one process step [13].

Other researchers have investigated the use of thixojoining to incorporate metal inlays into a workpiece and have found that it is possible to integrate hollow and two openended inserted parts into a workpiece [11]. Figure 1 shows a workpiece in which the female thread was completely filled with salt before the forming process. In this way, it is possible to integrate thin-walled inserted parts in a thixoforged work piece. With this method, it is also possible to vary the inner thread or form of the bore, for example, with inner toothed gearings or undercuts. Further investigations show the applicability of this type of thixojoining for pieces used in the construction of part of a vehicle bumper [14]. The piece illustrated in Figure 1 represents the joint from the long beam to the shock absorber beam in a car. In this shock

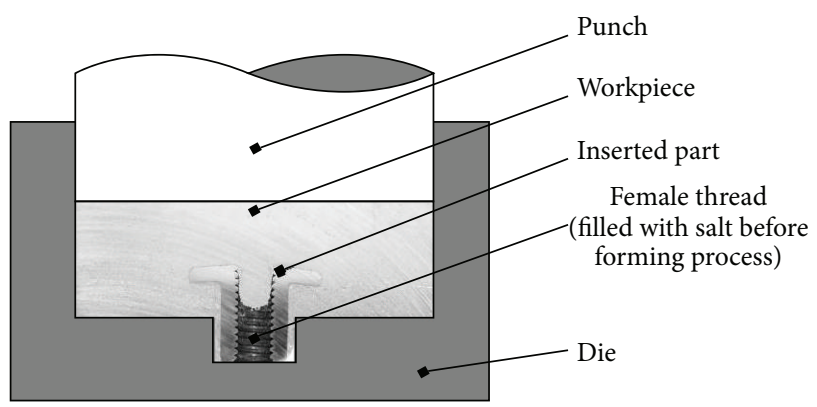

FIgURE 1: Female thread inserted in brass [11].

absorber, cylindrical material accumulations are integrated in the area of the endings. This method has already been approved in similar form for use in the serial production of cast workpieces.

By using the semisolid joining technique with constant pressure, it is possible to join metal/metal composites. Liu et al. $[15,16]$ carried out extensive experiments by using the semisolid joining technique. They demonstrated that the joining of stainless steel and semisolid aluminium alloy can be successfully realized and that during the joining period a new type of interfacial structure is constructed. The solid phase and liquid phase of the aluminium are joined with the stainless steel by turns along the joining interface because of the different diffusion ability of the solid and liquid phases of aluminium alloy. As a result, a new type of nonequilibrium diffusion interfacial structure is constructed at the interface of the stainless steel and aluminium alloy.

An intensive investigation into combining aluminium alloys with aluminium and steel alloys was conducted by Kiuchi et al. $[17,18]$. Through experiments to insert simple geometric forms such as pins and fins it was shown that the embedding of inserts is a promising joining technique. The low viscosity and good flow behaviour allow the inserts to be covered by the semisolid base material. An interesting result was that there was higher joining strength with decreasing content of the liquid fraction. This highlights a significant advantage compared to compound casting and was explained by the existence of intermetallic phases that result because of the diffusion and welding processes that take place at the contact area between the base material and insert. Table 1 shows the semisolid joining experiments undertaken by Sugiyama et al. [19].

In case 1, the joining of aluminium alloy, cast iron, or stainless steel of a base blank with metallic articles such as steel balls and short-cut steel fibres and with nonmetallic materials such as ceramic, glass, tile, and stone was realized when the base blank was in the semisolid state, and the particles and short fibres were inserted into the base blank under pressure. Applications for the resultant products include a surface hardening material, an abrasion-resistant material, a heat-resistant material, or a decorative material. In case 2 , the joining of the aluminium alloy of a base blank with wire pins or sheet fins of aluminium alloy, copper alloy, or stainless steel was performed. The base blank was also in the semisolid state, and wire pins or sheet fins were inserted into the base blank. The main application for the resultant products is as 
TABle 1: Previous semisolid joining undertaken by Sugiyama et al. [19].

\begin{tabular}{ccc}
\hline & $\begin{array}{c}\text { Base blank material (semisolid } \\
\text { state) }\end{array}$ & Joined material (solid state) \\
Case 1 & $\begin{array}{c}\text { Aluminum alloy (A2011); cast iron } \\
\text { (FC, FCD); stainless steel (SUS304, } \\
\text { SUS316) }\end{array}$ & $\begin{array}{c}\text { Short cut steel fiber; steel ball; } \\
\text { ceramics particle; stainless steel } \\
\text { wire; craft glass bar, plate, bead, and } \\
\text { frit; tile; stone }\end{array}$ \\
Case 2 & Aluminum alloy (A2011) \\
Case 3 & Aluminum alloy & Aluminum alloy wire, fin, and \\
sheet; copper alloy wire; stainless \\
steel wire, fin
\end{tabular}

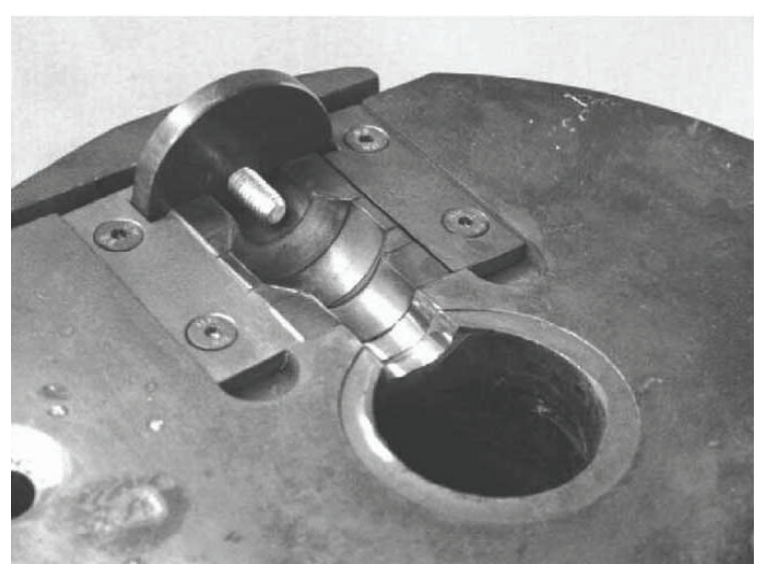

(a)

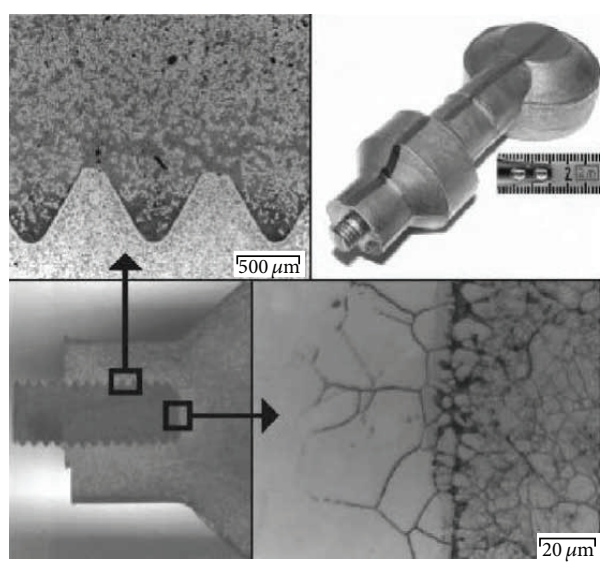

(b)

FIgURE 2: Lower die (a) and produced part with imagery of microstructure at interface (b) [20].

a heat exchange device. In case 3 , bosses or flanges made of aluminium alloy were joined to a base blank of aluminium alloy. In this case, the base blank was in the solid state and the boss or flange was in the semisolid state and was joined to the base blank under pressure.

Further investigations by Kopp and colleagues in the field of semisolid joining revealed the possibility of producing prototype components by combining the forming operation with the simultaneous insertion of additional components [20]. With this technology, it is possible to shorten conventional process chains and to create a new generation of components. With the application of the semisolid joining technique a new kind of composite component could be produced. Furthermore, the authors proposed the idea of combining forming and joining in one single process and proved its feasibility for a steel-steel combination (stainless steel screw in an M2 tool steel part) and its feasibility has been proved [20]. By using this special technique, additional functional components can be directly connected to a forged part thereby creating completely new classes of producible components. Metallographic analyses showed a good connection between the bulk material and the inserts without any pores at the contact area. Only at the border area did a change in the grain size indicate a thermal interaction in the form of a heat-affected zone, as shown in Figure 2.

Further research was conducted to investigate the possibility of joining lower melting point materials such as copper-based alloys [21]. The utilized base materials were two different steel alloys while the inserts were made of steel and copper-based alloys. Due to the excellent flow behaviour of the semisolid materials these were successfully combined, as shown in Figure 3. While the result achieved by Hirt et al. [21] was of good quality, the main challenge faced by researchers developing this technology for other materials has been finding a way to embed the inserts into the semisolid matrix without the geometry of the components being destroyed due to deforming or remelting. Experiments with different combinations of materials have demonstrated the general feasibility of this process but also have highlighted that critical issues such as crack initiation or the remelting of inserts have 


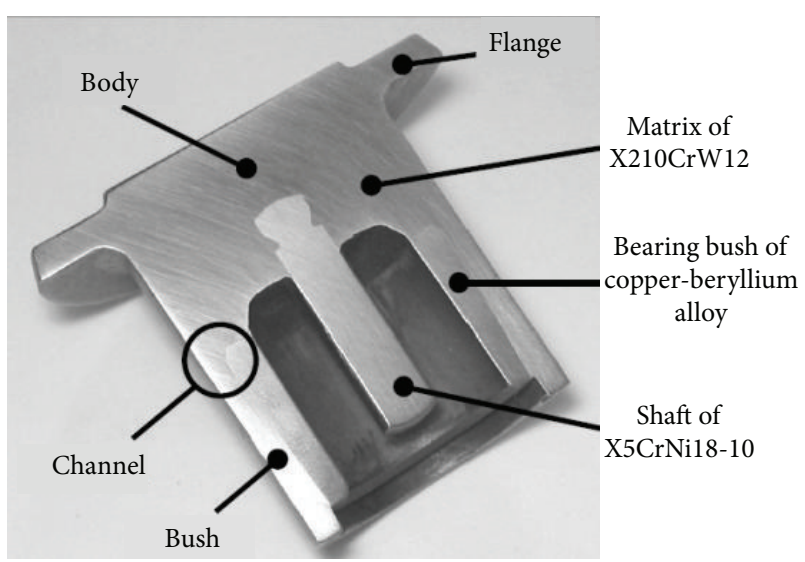

FIgURE 3: Thixojoined demonstrator part of X210CrW12 with integrated functional elements (shaft: X5CrNi18-10, bearing bush: copper-beryllium alloy) [13].

to be considered in the design of a component. These issues arise because the material properties of the base materials are highly influenced by the cooling velocities. Also, hardening effects could be caused by the fast cooling of the materials used or even by the influence of the inserts. On the one hand, the heat transfer into the inserts causes hardness to decrease and, on the other hand, in case of the copper-based alloys, remelting of the insert can occur at hot spots such as edges. Therefore, further investigations have to be undertaken to determine the limitations of the process window for a range of suitable materials. Also, the connection quality and the joining mechanism for steel components have to be analysed in basic experiments.

The research effort has concentrated on the modelling of the process in order to achieve a better estimation of the actual temperature distribution and to provide an initial temperature field for the simulation of the forming operation and on developing a model that can be used for process optimization. For instance, Baadjou et al. [22] derived input parameters for their finite element model, which included the whole process chain beginning with the heated billet and ending with the forming operation, by using Forge 2 software, which is based on Lagrange equations and uses a viscoplastic material behaviour to consider the strain rate and temperature dependence of plasticity. Therefore, the temperature distribution directly before forming has to be taken into account for numeric modelling of the forming operation, which can only be achieved by simulation of the complete process chain. This work provided a series of comparisons of the simulated load-displacement curves with experimental ones for compression tests on semisolid steel at different temperatures. The results for the joining of inserts with a semisolid matrix revealed that there were temperature gradients in the matrix component as well as in the inserts, which proves the general feasibility of this approach, as shown in Figure 4. The authors found that both ferrous and copper-based alloys are suitable for thixojoining with the cold-work tool steel, $\mathrm{X} 210 \mathrm{CrW} 12$. The temperature fields of the inserts are below the materials solidus after the forming operation so that damage by melting can be avoided. The inserts only reached a higher temperature in the subsequent phase of compression and solidification.

2.2. Joining Metals by Using Semisolid Slurries. Some researchers have attempted to incorporate the semisolid joining principle into the welding process as a method to join materials together. Thus far efforts in this direction have been restricted to $\mathrm{Sn}-\mathrm{Pb}$ alloys. For instance, Mendez and Brown [23] used $\mathrm{Sn}-5 \mathrm{wt} \% \mathrm{~Pb}$ (mass fraction) slurries as a filler and applied it on the joint groove to join bars of $\mathrm{Sn}-15 \mathrm{wt} \% \mathrm{~Pb}$ model alloy, as shown in Figure 5. The microstructure of the joined cross-sectional area showed excellent metallurgical joining with the interface connection and smooth and homogeneous welding between the bars and filler metal without defects such as pores, oxide interface, cracks, or adverse effects in the heating zone. The authors performed crossjoint tensile tests, the results of which showed that the joint strength was comparable to that of the bulk material. The key factors to consider in order to obtain a good joint when using this process are the substrate and slurry temperature, as well as the absence of superficial oxides or contaminants. In this process, the substrate must be preheated locally before the slurry fills the weld groove, so that the portion of the substrate in contact with the oncoming slurry is also in the semisolid state. This type of joining has the distinctive advantage of enabling a controlled flow during deposition. In addition, operating temperatures and thermal gradients are smaller than in arc welding. Other advantages of this process are that it allows the creation of a joint with an equiaxed microstructure, it allows the deposition of large amounts of filler metal in one pass, and there is absence of fumes and spatter [24]. On the other hand, the process has some limitations in its current form like the heating of the substrate is not localized, so the temperature of the bulk of the bars to be joined is raised to a semisolid temperature. Another limitation is that the rheocaster for slurry production is limited in that it can only be used for low melting point alloys such as the Sn-Pb alloy in [24].

2.3. Semisolid Stir Joining. Semisolid stir joining (SSSJ) is a new joining process that was developed to improve upon existing bonding technologies. Specifically, this process was patented to overcome the deficiencies of the then-current joining techniques which were based on friction stir welding. A technique to achieve a globular weld structure by stirring the localized semisolid zone during the butt-joining of Pb-15 wt\%Sn, zinc AG40A die cast alloy, and A356 has been reported by Amirkhiz, Narimannezhad, and Alvani, respectively [25-27]. A heating element was embedded in a castable ceramic block so that a stream of gas could pass closely around the hot element length. First, hot nitrogen gas flow through a precise ceramic nozzle was used to create a localized semisolid pool. At this stage a fine stirrer was introduced into the weld seam in order to mix the two sides into a single uniform joint, as shown in Figure 6. The substrates were moved in the direction of the joint line by a small trolley to prevent the nozzle from deviating away from the joint line and to maintain its distance and angle 


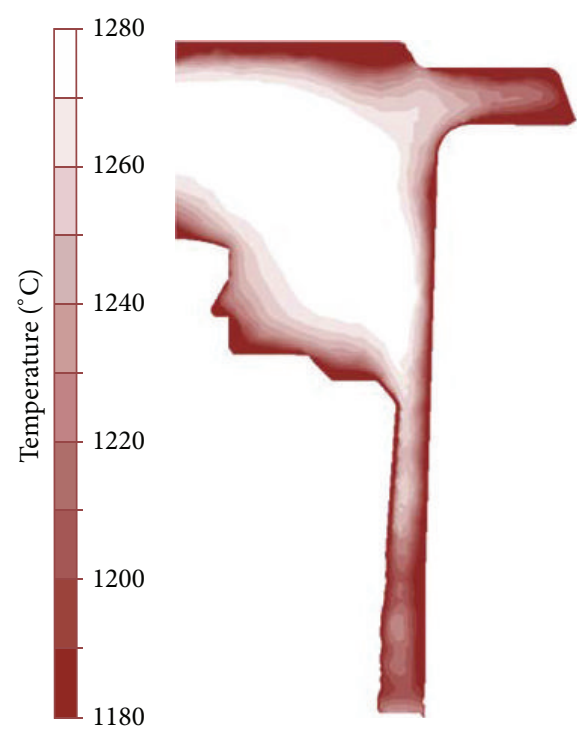

(a)

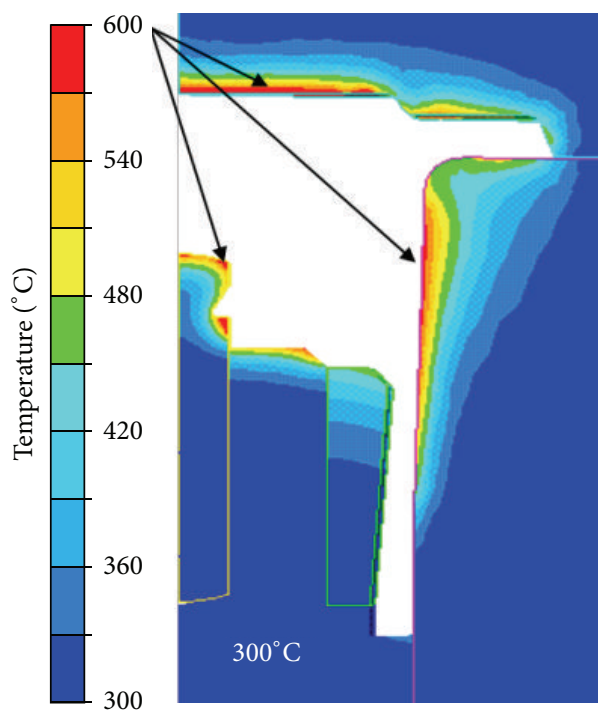

(b)

FIGURE 4: Simulated temperature gradient in (a) matrix of formed X210CrW12 and (b) tools and inserts after joining [22].

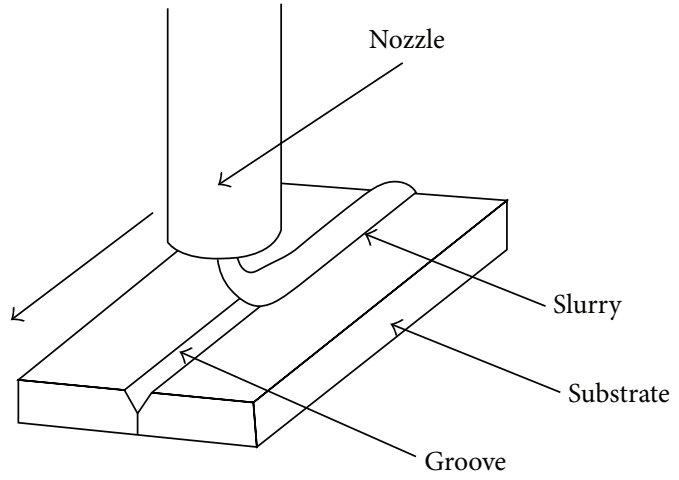

FIGURE 5: Joining metals using semisolid slurries [23].

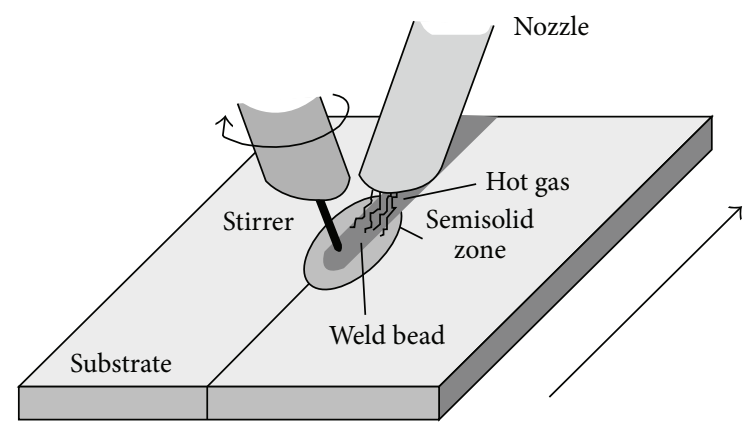

Figure 6: Schematic of semisolid stir welding process [25].

from the substrate. A fixture system was used to hold the two substrates together on the trolley. The results of shear punch tests and hardness tests showed that the local mechanical properties of the different zones had good strength in the weld metal zone and heat-affected zone. The authors also found that air entrapment in the pool could be reduced by controlling the speed of substrate movement and stirrer rotation under the nozzle. The variation in the strengths of each zone corresponded to the variation in the hardness values [28].

The critical parameters for obtaining a desirable joint in this method are gas flow, temperature control, stirrer rotation speed, and welding speed. For the rather short samples to be welded successfully, this process requires that the weld pool temperature is extremely accurate. The results showed that an increase in temperature improves the final welding properties. At liquid fractions of less than $50 \%$, joining is not fully practicable; the best mechanical properties are achieved with a liquid fraction of about $70 \%$.

Recently, there has been increasing interest in developing a vacuum-free SSSJ process, which allows a low joining temperature when applied to a semisolid base metal or semisolid filler metal. Xu et al. have carried out extensive experiments by using the SSSJ technique and have shown that the joining of SiCP/A356 composites with similar material or different materials such as 2024-aluminium alloy can be successfully achieved by using a $\mathrm{Zn}$-Al eutectic filler metal in air with the aid of mechanical stirring $[29,30]$. The two substrates and $\mathrm{Zn}$-Al filler metal were heated up to the semisolid temperature range of the $\mathrm{Zn}-\mathrm{Al}$ filler metal by a resistance heating plate. In order to mix the filler metal with the base metal on either side to create a single uniform joint, a stirrer was introduced into the weld seam, as shown in Figure 7. However, the metallurgical joints formed between the filler metal and the base metal on the interface of oxide was disrupted. Moreover, the oxide film on the surface of the aluminium alloy was more thoroughly disrupted and removed than that of the surface of the composites with existing of $\mathrm{SiC}$ particle. The filler metal was extruded and 


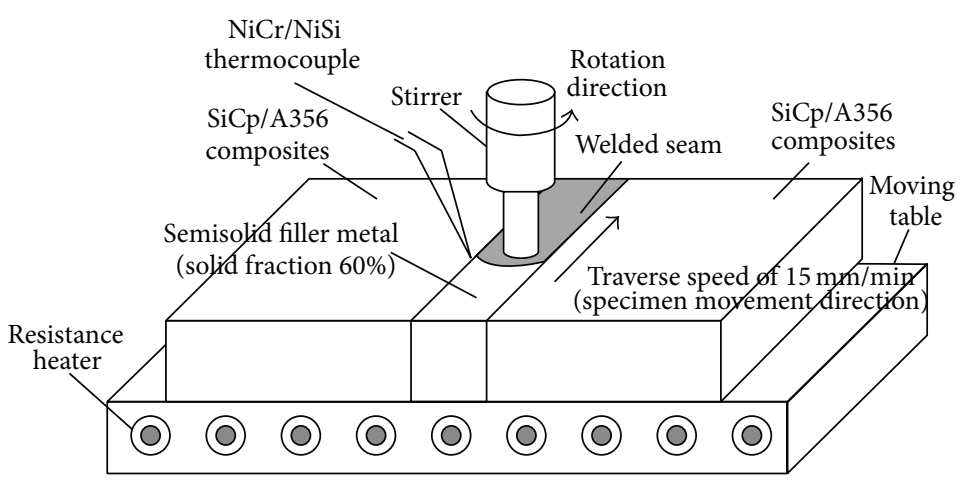

FIGURE 7: Schematic of semisolid stirring brazing [43].

impacted intensively on the two surfaces of the base metal during stirring. It can be found that oxide film on the surface of the composites can be disrupted and removed.

The experimental results showed that the tensile strength of the joints increases with increasing stirring rate. This suggests that increasing the stirring rate will promote the disruption of oxide film on the surface of the composites and thereby enhance the metallurgical bonds at the joint interface. In addition, increasing the stirring rate will also promote the formation of a fine brittle $\mathrm{g}$ - $\mathrm{Zn}$ phase and its uniform distribution in bond. When this occurs, the solid fraction of the filler alloy is about $60 \%$. However, with increasing temperature the solid fraction of the filler alloy decreases quite significantly. In this process, the joining temperature is critical to achieving an ideal shape and a good microstructural interface at the joint $[31,32]$.

Similarly, Hosseini et al. [33] have also carried out extensive experiments on SSSJ, in this case AZ91 alloy, by using mechanical stirring and a Mg-25 wt $\% \mathrm{Zn}$ interlayer without protecting the weld with any inert gases or fluxes. Their proposed method showed great potential for use as an alternative joining method for Mg-based alloys. A sound welding cross-section was obtained after stirring due to an interruption of the oxide layers, whereas joining was not observed without stirring. On the other hand, the bending strength of the joint was just $67 \%$ of that of the base metal because of coarse eutectic and a large amount of porosity. Thus, fractures in the weld metal occurred in the eutectic phase or as a result of the high level of porosity. However, the globules were not cracked.

More recently, an attempt was made by Petkhwan et al. [34] to investigate the semisolid state butt-joining of SSM A356 aluminium alloy without using filler under a normal atmosphere. The butt-joint of SSM A356 was heated by an induction heating coil to create a localized semisolid pool, as shown in Figure 8 . Then a stirrer was applied into the joint seam in order to mix the weld metal. Experimental results showed that with an increase in stirring rate the surface of the joint became smoother. The weld metal consisted of the globular microstructure and also voids and the average $\alpha$-Al particle size after SSSJ was larger than that of the base metal. The density of weld metal zone increased by appropriate stirring. The best tensile strength was achieved with $1750 \mathrm{rpm}$,

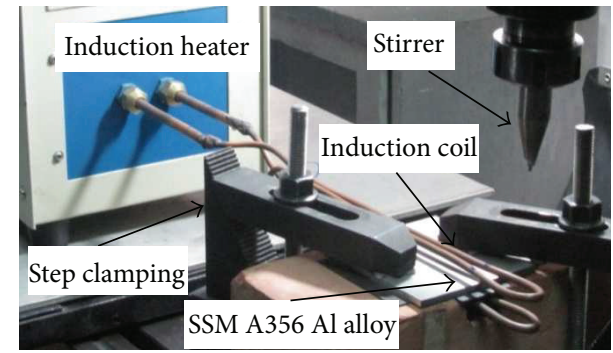

FIGURE 8: Semisolid state joining equipment [34].

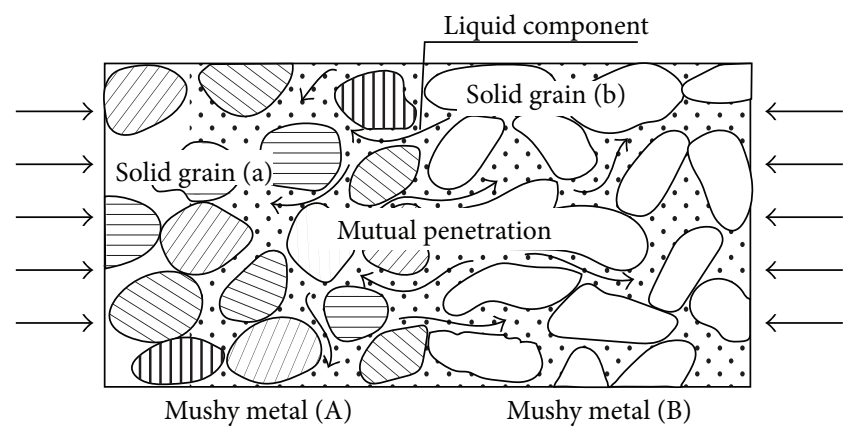

FIGURE 9: Joining of semisolid metals [8].

$70 \mathrm{~mm} / \mathrm{min}$ for $103.4 \mathrm{MPa}$, that is, about $60.8 \%$ of that of the base metal.

2.4. Semisolid Diffusion Joining. Kiuchi and Kopp [8] supposed that two pieces of semisolid metal could be joined together by utilizing a peculiar characteristic of the metals' liquid components. In their proposed method, when the interfaces of two metals are pressed together, the liquid components present in both sides of these "mushy metals" penetrate and diffuse through the interface and then solidify together, as illustrated in Figure 9. The authors showed that it is possible to join two semisolid metals through the mutual penetration of liquid components and solidification as one body.

Intensive investigations to achieve a high-quality globular join structure were undertaken by Mohammed et al. [35] in 


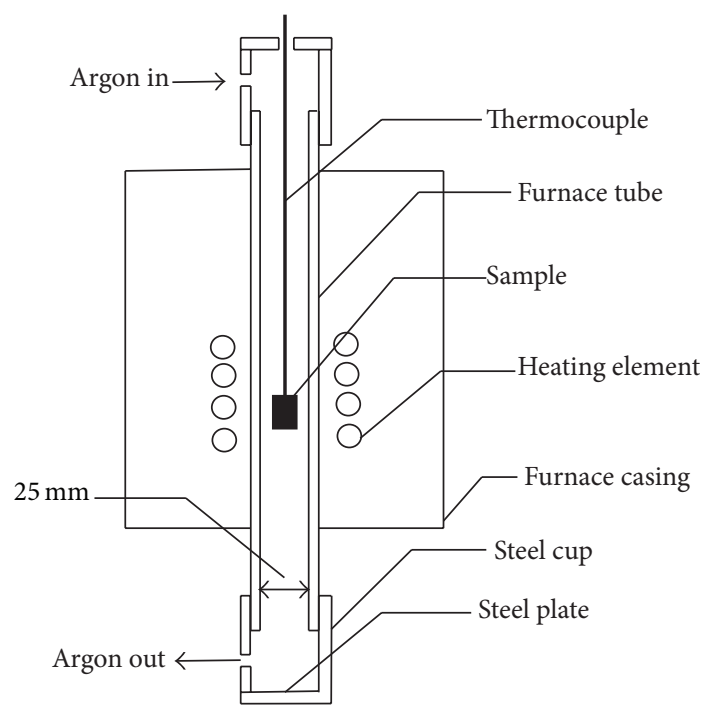

Figure 10: Schematic of furnace setup for remelting experiment [44].

semisolid diffusion joining (SSDJ). Their research explored the possibilities of joining semisolid AISI D2 tool steel with functional elements of the same material as well as with other materials such as AISI 304 stainless steel by using a direct partial remelting (DPRM) technique (when the as-received metal is directly heated to the semisolid state) $[36,37]$. The joining process was performed by using a vertical, hightemperature carbolite furnace with a protective atmosphere of argon gas. When the furnace had reached the predefined temperature, the two-part sample (base and insert) was lowered into the hottest place of the furnace by using a chromel wire and held there for a predefined time, after which it was subjected to air cooling to room temperature, as shown in Figure 10.

This process has four distinct characteristics: (1) adhesion, (2) wetting, (3) spreading, and (4) diffusion attraction, whereby

(1) the joining or uniting of an assembly of two or more parts into one structure is achieved;

(2) the assembled parts are directly heated to a temperature high enough so that they are between solidus and liquidus;

(3) the liquid phase spreads into the joint and wets the metal surfaces;

(4) the parts are cooled to freeze the liquid phase of the metal, which is held in the joint by capillary attraction and anchors the part together.

Based on the results of the experiments conducted in this study of D2-D2 joining, the use of this technique can produce homogeneous properties with high surface quality. Furthermore, a smooth transition from one part to the other is obtained with no evidence of microcracking or porosity. As for the interfacial reactions that occurred during the heating process, these provided elemental diffusion across the interface and the eutectic liquid spread between the joined surfaces to achieve what appears to be good join at the interfaces of both parts of the steel $[38,39]$.

On the other hand, a study of D2-304 joining revealed that a new type of nonequilibrium diffusion interfacial structure was created at the interface of the two different types of steel [40]. Nonequilibrium diffusion occurred due to the difference in chemical composition of the two metals and the huge difference in the liquid fraction percentage of the two metals at the same temperature. As for the interfacial structure, both metals exhibited different reaction and diffusion abilities between solidus and liquidus whereby the base metal was connected to the insert metal along the joining boundary to achieve what appears to be a perfect join at the interfaces of both metals, as shown in Figure 11.

This study, which simply joins two parts, shows that SSMJ is a promising joining technique that enables face-toface joining rather than line-to-line joining, which occurs in conventional welding. Therefore, this method not only prevents corrosion at the interface of the components but also confers a better shape than welding. The high diffusion ability, low viscosity, and good flow behaviour make it possible to obtain this type of join. The work of [40] confirmed that avoidance of a dendritic microstructure in the semisolid joined zone and high-quality joined components can be achieved without the need for force or complex equipment that typify conventional welding processes. The quality of the transition region between the two parts appears to be high, although additional work will be necessary to optimize the quality of the join.

Similarly, Kalaki et al. [41, 42] have also carried out more effort on thixojoining with the aim to provide globular joining structure in semisolid state by employing AISI D2 and M2 tool steels via applying an approximately $1 \mathrm{MPa}$ constant compressive stress at nil strength temperature of D2 and direct partial remelting in furnace with argon controlled atmosphere. Experimental results showed that the alloy with low solidus temperature in the semisolid overlap zone is highly affected by temperature experiment. This is due to high values of liquid phase generation in microstructure. Furthermore, In thixojoining situations carbides size and globular microstructure are helping in improvement of interface mechanical properties. The shear test of thixojoining parts showed the high bonding strength interface in $1300^{\circ} \mathrm{C}$ but the fracture strain or displacement in $1300^{\circ} \mathrm{C}$ is lower than $1280^{\circ} \mathrm{C}$. These are related to carbides dissolution increasing in $1300^{\circ} \mathrm{C}$ which is decreasing the fracture strain. The results obtained from investigations proved a good joining quality. The current work confirmed that a joint with suitable globular microstructure and high bonding quality components can be obtained in $1300^{\circ} \mathrm{C}$.

\section{Applications of SSMJ Process}

The SSMJ process can be utilized for manufacturing various near-net-shape products with complex shapes and geometries where brazing, welding, and diffusion brazing cannot be used for various reasons (e.g., low melting temperature 


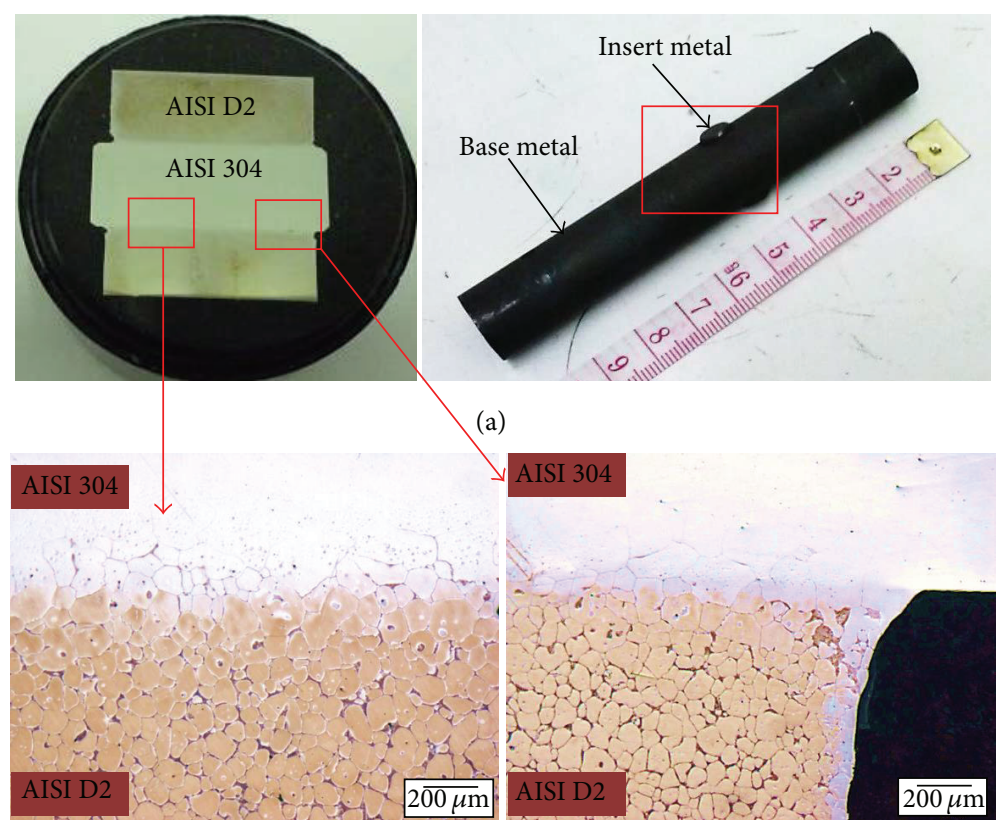

(b)

Figure 11: Produced part (a) with microstructure at interface (b) [45].

joint, insufficient resulting mechanical properties, and unacceptable plastic deformation). In addition, this process can contribute to the development of new types of products as well as materials. Various applications have been considered for this new joining process such as shock absorbers for cars [14] and a slider system element, roller way components, and heating radiator components (heat-sinks) [3]. This joining technology can be applied to join different shapes of craft glass and stones onto plates, bars, and a range of blanks and billets. These products can be applied to decorate a wide variety of items such as wall plates, floor panels, and smaller articles and accessories. In addition, glass/metal joining products have great potentialities for adding other functional properties to materials to create lubricated, antiwear, heatresistant, or corrosion-proof items [19]. Table 2 presents some of the types of similar and dissimilar materials that have been joined by using the SSMJ process.

\section{Advantages and Disadvantages of SSMJ Compared to Conventional Processes}

As stated earlier, the many potential benefits of thixojoining have encouraged different researchers to carry out feasibility studies on various components. Furthermore, the SSMJ of dissimilar alloys/metals has attracted extensive research interest due to potential engineering benefits and SSMJ's ability to overcome the problems associated with conventional welding. Indeed, for some material systems, joint properties and performance capabilities that are difficult or impractical to achieve using conventional joining methods are possible with SSMJ. However, on the other hand, in the conventional welding process, which involves fusion of a component with the base metal, the liquid metal solidifies as heat is extracted via weld pool walls. Also, the morphology of the growing solid-liquid interface is typically dendritic and the natural progression of solidification often leads to internal structural defects, such as entrained oxides or shrinkage porosities, which combine to yield a weld metal of relatively poor mechanical properties that is inferior to the microstructures that can be achieved through casting.

The semisolid joining of alloys has the potential to avoid many of the problems mentioned above because the solidification and heat transfer processes are basically different than those of typical welding. Therefore, it is important not only to show the feasibility of SSMJ but also to delineate its advantages over other techniques. The main advantages of SSMJ are outlined below:

(1) SSMJ, by combining the forming operation with the simultaneous insertion of additional components in the semisolid matrix, has the potential to produce a range of new components with greater functionality and complexity from different composites. Moreover, with this technology it is also possible to shorten conventional process chains when producing such components [21].

(2) SSMJ can be used to successfully embed simple geometric forms such as thin sheets, small pins, and fine wires into a base material because the low viscosity and good flow behaviour that is achieved through this technique makes it possible for the inserts to be fully covered by the semisolid base material. In addition, this joining process allows surface-tosurface joining rather than the line-to-line joining of conventional welding. Therefore, it prevents corrosion at the interface of the components and confers 
TABLE 2: Types of materials joined by SSMJ.

\begin{tabular}{|c|c|c|c|}
\hline \multirow[b]{2}{*}{$\mathrm{a}$} & Substrate & \multirow{2}{*}{ Interlayer combination(s) } & \multirow{2}{*}{ Reference(s) } \\
\hline & $\mathrm{b}$ & & \\
\hline CuZn40Al2 & Tool steel & & {$[14]$} \\
\hline Stainless steel & Aluminum alloy & & {$[15]$} \\
\hline $\begin{array}{l}\text { Aluminum alloy, cast iron, or } \\
\text { stainless steel }\end{array}$ & $\begin{array}{l}\text { Particles, balls, short fibers of } \\
\text { metallic or nonmetallic } \\
\text { materials, such as ceramic, glass, } \\
\text { tile, or stone, aluminum alloy, } \\
\text { copper alloy, or stainless steel }\end{array}$ & & {$[5,12,17,18]$} \\
\hline Stainless steel & M2 tool steel & & {$[20]$} \\
\hline $\begin{array}{l}\text { X210CrW12, 100Cr6, and } \\
\text { X5CrNil18-10 }\end{array}$ & $\begin{array}{l}\text { 9SMn28, CuCo2Be, CuSn12, and } \\
\text { GBZ12 }\end{array}$ & & {$[13,21]$} \\
\hline Sn-15 wt\%Pb & Sn-15 wt $\% \mathrm{~Pb}$ & $\mathrm{Sn}-5 \mathrm{wt} \% \mathrm{~Pb}$ & {$[10]$} \\
\hline $\mathrm{Pb}-15$ wt $\% \mathrm{Sn}$ & $\mathrm{Pb}-15$ wt\%Sn & & {$[25]$} \\
\hline Zinc AG40A die cast alloy & Zinc AG40A die cast alloy & & {$[26]$} \\
\hline A356 & A356 & & {$[27]$} \\
\hline SiCP/A356 composites & 2024 aluminum alloy & $\mathrm{Zn}-\mathrm{Al}$ & [29] \\
\hline SiCP/A356 composites & SiCP/A356 composites & $\mathrm{Zn}-\mathrm{Al}$ & [43] \\
\hline AZ91 alloy & AZ91 alloy & $\mathrm{Mg}-25 \mathrm{wt} \% \mathrm{Zn}$ & {$[33]$} \\
\hline A356 aluminum alloy & A356 aluminum alloy & & {$[34]$} \\
\hline D2 tool steel & D2 tool steel & & {$[39]$} \\
\hline D2 tool steel & 304 stainless steel & & {$[40]$} \\
\hline D2 tool steel & M2 tool steel & & {$[42]$} \\
\hline
\end{tabular}

a better shape than welding. Furthermore, SSMJ can be used to embed metallic or ceramic materials for use in reinforcement or as bearing systems [12].

(3) The most distinctive advantage of the SSMJ process is that the operating temperatures and thermal gradients are smaller than in arc welding and this opens up the possibility of combining semisolid materials with different solidus temperatures. For instance, parts made of copper-based alloys, which have a lower solidus, can be inserted into a higher-solidus base material such as steel alloys. This advantage is especially important for temperature-sensitive materials whose microstructures can be damaged by too much thermal energy input and therefore need to be joined at lower temperatures $[10,39]$.

(4) Some welding problems such as an inhomogeneous weld microstructure, sputtering, and high process temperature have been solved and satisfactory mechanical properties have been gained when certain alloys have been joined in a semisolid state $[10,42]$.

(5) SSMJ results in a globular microstructure, which offers the possibility of joining rather thick plates autogenously. The SSMJ process also dramatically decreases welding distortions because the welding temperature is below the liquidus temperature and the temperature difference between the weld pool and the bulk substrate is smaller than in commonly employed fusion welding methods. Moreover, the relatively lower welding temperature in SSMJ reduces the heat-affected zone. Another advantage of this process is the absence of fumes and spatters [21].

(6) For some material systems, the required bond properties and performance capabilities are difficult or impractical to achieve using conventional joining methods but are possible with SSMJ, which is often used in high-stress, high-temperature applications where brazing, welding, and diffusion brazing cannot be used for various reasons (e.g., low melting temperature joining, insufficient resulting mechanical properties, and unacceptable plastic deformation) [29].

(7) Another advantage is that the SSMJ process often has microstructural and therefore mechanical benefits in that the properties of microstructure of the produced join are often similar to those of the base material. In fact, in some cases the joint area becomes indistinguishable from other grain boundaries due to significant diffusion at high temperature. Such joints are often as strong as the bulk substrate material, or stronger, causing the joined assembly to fail in the substrate material rather than in the joint [33].

The advantages described above are not exhaustive by any means and it is conceivable that other advantages will become apparent when the full potential of SSMJ processing is taken into account from the first steps of a component design.

Despite the clear benefits that can be gained by using the SSMJ process, it has some limitations in its current form, like 
the difficulty to control the temperature and solid fraction during the joining process [10]. Heat transfer into the inserts decreases hardness and remelting of the insert can occur at hot spots such as edges. Where a high solid fraction is present, the liquid phase of the base metal must wet the insert. In addition, some parts at the border area change in terms of their grain size, which indicates a thermal interaction in the form of a heat-affected zone [13]. Matching the thermal expansion coefficients of the combined elements is sometimes necessary to prevent thermally induced stresses and cracking. In addition, when intermetallic formation is done in this process, and if the reaction layer is thick, it tends to be brittle and can degrade the joint strength.

However, most of the disadvantages of the SSMJ process can be overcome by developing an appropriate methodology, which includes finding a way to optimize the joining parameters and enlarging the size of the process window so that SSMJ can be applied to a wider range of suitable materials. Achieving process optimization often requires much experimentation and there is therefore still a need for further investigations in this area.

\section{Discussion}

5.1. Addition of Functionality. Generally speaking, previous studies have demonstrated the feasibility of using the SSMJ technique to join materials that have both simple and complex geometries. However, analyses of the quality of the produced components have shown that the technique is still limited in terms of the range of materials that can be utilized and the diversity of the geometries of the inserts that can be fused or embedded in this way. One of the important issues that has to be clarified in further investigations is the influence of the thermal transient, which determines the mechanical properties of the component and its inserts, and thus affects the quality of the join at the contact areas between base material and insert [13]. Also, the development of the microstructure of the solidified material is influenced by the geometrical conditions, which also cause differences in the mechanical properties. Furthermore, there could be as yet unforeseen design restrictions that would need to be considered in order to avoid the process damaging the inserted components.

A tight mechanical closure between the joining elements and the matrix has been achieved in most of the material and parameter combinations in the reported studies [21]. This shows that various kinds of joining elements made from different materials (e.g., higher melting steel, nonferrous metals) could be combined to produce a variety of products suitable for different purposes such as a screw thread or a nut for assembling, a gliding functional element, or a reinforcing element [20]. The thixojoining technique opens up the possibility of designing a range of new parts and also has an additional advantage in that it can shorten processing time. However, in order for this new production technology to be implemented in industry, the resulting products need to be subjected to a detailed analysis (including, among others, dynamic fatigue tests, bending tests, and pull-out tests) to quantify and ensure quality. Nevertheless, the potential of this new technology is huge and includes the capability to produce specially designed alloys and composites, to combine the forming and joining processes, and to reduce production costs and energy consumption.

\subsection{Joining Metals by Using Semisolid Slurries. Semisolid} fillers have the unique advantage of enabling a controlled flow during deposition, even for deposition rates that cannot be contained by capillary forces. In addition, operating temperatures and thermal gradients are smaller than in arc welding. The other main advantages of this process are that it allows the creation of a joint with an equiaxed microstructure, it allows the deposition of large amounts of filler metal in one pass, and there is absence of fumes and spatter [10]. On the other hand, the process has some limitations in its current form. First, the heating of the substrate is not localized, so the temperature of the bulk of the bars to be joined is raised to a semisolid temperature. Another limitation is that the rheocaster for slurry production is limited in that it can only be used for low melting point alloys such as the $\mathrm{Sn}-\mathrm{Pb}$ alloy.

Future efforts in this direction could include the application of this technology to alloys of commercial interest with higher liquidus temperatures and better structural qualities, such as ferrous alloys or aluminium alloys that have been studied theoretically in [10]. Further work is also required to determine the best method for preheating the joint groove because the heat content of the slurry by itself is not enough to soften the interface adequately. A suitable preheating method should also prevent groove face oxidation or contamination. Possible preheating methods could involve allowing hot inert gas or plasma to impinge on the groove immediately before the deposition of the slurry; the application of such a method would also provide a protective atmosphere and ensure the absence of slag. Practical considerations also remain to be addressed, especially from the point of view of improving the ease of use of the semisolid slurry dispenser.

5.3. Semisolid Stir Joining. Semisolid stir joining is newer development in semisolid joining technology. In the semisolid joining process, a semisolid substrate can be joined under constant pressure. Usually, a join with a linear interface appears as a result of using traditional techniques, whereas a joint with a nonlinear interface can be realized by SSSJ, which enhances the strength of the joint interface. In the vibration brazing process [33], an amount of porosities can easily become entrapped in the joints due to the reciprocal periodic vibration. So, additional technology is required to remove the resultant voids. In contrast, joints with very few porosities can be obtained by using a semisolid stir joining process.

In semisolid stir welding [32], indirect joining of semisolid substrates with the aid of mechanical stirring was carried out. In SSSJ during butt-joining there are different ways to create a localized semisolid pool either by using a gas heating system to heat up the nitrogen gas (shielding gas) or a resistance heating plate or an induction heating coil (vacuumfree). In comparison with the process, with semisolid filler metal being applied in the joining process, a lower joining 
temperature can be realized in the stir brazing, which can avoid creating weaknesses in the structure of the substrate and reduce distortion. In addition, an interface reaction can be avoided by the application of a semisolid filler metal in the stirring brazing phase, which otherwise could easily appear when indirectly joining dissimilar substrates. So, an ideal joint with a nonlinear interface and few porosities can be obtained by semisolid stir brazing at a lower temperature. Also, with increasing temperature, the solid fraction of the filler metal decreased quite significantly. The joining temperature is critical in achieving an ideal shape and a good-quality microstructural interface for the joint during stirring brazing.

While there are several benefits of using variations of SSSJ as outlined above, the process also has limitations in its current form. First, the optimum parameters have to be changed according to the specimen size. It is not possible to maintain the same parameters for a long distance of welding as the temperature of the whole specimen increases; therefore, it is necessary to develop a more sophisticated process monitoring system which changes the parameters with time if SSSJ is going to be used successfully on an industrial scale. Moreover, the tools used in this process need to be modified to provide a better and smoother mixing of the substrates and prevent the formation of pores. Friction stir welding tools could be considered as a starting point to design suitable tools for SSSJ from. Another limitation is that the heating medium that has been used in studies thus far [33] is limited in its capabilities to low melting point alloys. One possible alternative could involve allowing hot inert gas or plasma to impinge on the joint seam. Such a method would also provide a protective atmosphere and ensure the absence of slag.

5.4. Semisolid Diffusion Joining. In order to enhance the potential of the SSMJ process and also to overcome the problems associated with conventional welding methods, a method to join two metals in a thixotropic state (SSDJ) was developed [35]. This process can produce homogeneous properties with high surface quality and prevents a dendritic microstructure being created at the join zone. This process has four distinct characteristics: adhesion, wetting, spreading, and diffusion attraction. By using this type of thixojoining process, there is no need for force or complex equipment when compared to conventional welding processes such as friction welding. The quality of the transition region between the two parts appears to be high, although additional work will be necessary to optimize the quality of the join. However, based on the results of the experiments conducted thus far [38], the use of this thixojoining technique can create a fine interfacial diffusion along the joining boundary between the base blank and insert. Furthermore, a smooth transition from one metal to the other is achieved through the formation of new columnar crystal growth near the convergence zone. Importantly, the transition occurs without evidence of microcracking or porosity.

Future efforts in this direction could include the application of this technology to alloys of commercial interest with higher liquidus temperatures and better structural qualities, such as ferrous alloys or aluminium alloys including those studied theoretically in [39]. Further work is also required to apply this technology by using an induction heating coil in a butt-joint to create a localized semisolid pool to determine the best method for the DPRM technique.

\section{Conclusion}

The semisolid metal joining (SSMJ) process or thixojoining process is a relatively new joining process that has been developed based on the principles of the semisolid metal (SSM) processing to improve on traditional joining processes. The semisolid joining processes can be categorized into the following types: (a) addition of functional features, (b) joining metals by using semisolid Slurries, (c) semisolid stir joining, and (d) semisolid diffusion joining. This paper has reviewed the findings in the literature to date in this evolving field, specifically the experimental details, technology considerations for industrialization, and advantages and disadvantages of the various types of SSMJ methods that have been proposed thus far. It has also presented details of the range of materials that have been joined by using SSMJ. Furthermore, it has highlighted the huge potential of this process and future directions for further research. Based on the present review, the following conclusions can be drawn:

(1) The potential of SSMJ is vast and its advantages include the capability to process specially designed alloys and composites, to combine the forming and joining processes, and to reduce production costs and energy consumption. In addition, some welding problems such as inhomogeneous weld microstructure, sputtering, and high process temperature have been solved by employing this technique and satisfactory mechanical properties have been achieved when alloys have been joined in a semisolid state. All the works reviewed have improved our knowledge of the SSMJ process from an experimental point of view. They have also provided essential data that can be used to model the behaviour of semisolid steel. Indeed, the early results of analyses of the mechanical properties of thixoformed steel products give us confidence that it should be possible to produce parts of satisfactory quality.

(2) A rigid perpetual joining between the inserting elements and the matrix has been achieved in most of the material and parameter combinations in the reported studies. This shows that various kinds of joining elements made from different materials (e.g., higher melting steel, nonferrous metals) could be combined to produce a variety of products suitable for different purposes such as a screw thread or a nut for assembling, a gliding functional element or a reinforcing element. This thixojoining technique opens up the possibility of designing a range of new parts and also has an additional advantage in that it can shorten processing time.

(3) The prototypes from different projects demonstrate that the production of complex parts and the joining of different parts via SSMJ are generally possible, 
but improvements are still needed to enhance the properties of the components produced. To be able to transfer semisolid joining technologies to the industrial scale further detailed analysis (including, e.g., dynamic fatigue tests, bending tests, and pull-out tests) has to be carried out to quantify the quality of the connection achieved between materials.

(4) It is also necessary to pay some attention to finding ways to apply SSMJ to stone/metal composites not least because the properties of stone change with temperature. For example, some stone materials change colour, others become brittle, and there are those that break apart into pieces. While SSMJ is a specialized joining process that requires more resources to implement compared to typical joining processes, in some cases an SSMJ technique is the best or only way to join certain materials for specialized applications, so it is worth pursuing this line of inquiry.

(5) Finally, efforts are still needed to produce defectfree components in serial production at a competitive cost. In this field, there is still a great need for research to set a complete processing map that will lead to a better understanding of all the SSMJ process parameters and their possible impact on a part's microstructure and thus its mechanical properties. At present, the modelling of the SSMJ is not well developed because of the difficulties in obtaining experimental parameters, but the principles should be similar to those for modelling semisolid die forming in general. The advantages of SSMJ that have been highlighted in this paper are not exhaustive, so it is conceivable that other advantages will become apparent as research in this field evolves.

\section{Conflict of Interests}

The authors declare that there is no conflict of interests regarding the publication of this paper.

\section{Acknowledgments}

The authors would like to thank Universiti Kebangsaan Malaysia (UKM) and the Ministry of Education (MOE), Malaysia, for the financial support under Research Grants GUP-2012-040 and AP-2012-014.

\section{References}

[1] R. Sekharbabu, H. K. Rafi, and K. P. Rao, "Characterization of D2 tool steel friction surfaced coatings over low carbon steel," Materials \& Design, vol. 50, pp. 543-550, 2013.

[2] D. B. Spencer, R. Mehrabian, and M. C. Flemings, "Rheological behavior of $\mathrm{Sn}-15 \mathrm{pct} \mathrm{Pb}$ in the crystallization range," Metallurgical Transactions, vol. 3, no. 7, pp. 1925-1932, 1972.

[3] M. C. Flemings, "Behavior of metal alloys in the semisolid state," Metallurgical Transactions A, vol. 22, no. 5, pp. 957-981, 1991.
[4] R. Mehrabian and M. C. Flemings, "Die castings of partially solidified alloys," American Foundrymen Society Transactions, vol. 80, pp. 173-182, 1972.

[5] B. F. Quigley, G. J. Abbaschian, R. Wunderlin, and R. Mehrabian, "A method for fabrication of aluminum-alumina composites," Metallurgical Transactions A, vol. 13, no. 1, pp. 93-100, 1982.

[6] J. Y. Chen and Z. Fan, "Modelling of rheological behaviour of semisolid metal slurries. Part 3. Transient state behaviour," Materials Science and Technology, vol. 18, no. 3, pp. 250-257, 2002.

[7] K. S. Alhawari, M. Z. Omar, M. J. Ghazali, M. S. Salleh, and M. N. Mohammed, "Evaluation of the microstructure and dry sliding wear behaviour of thixoformed A319 aluminium alloy," Materials \& Design, vol. 76, pp. 169-180, 2015.

[8] M. Kiuchi and R. Kopp, "Mushy/semi-solid metal forming technology-present and future," CIRP Annals-Manufacturing Technology, vol. 51, no. 2, pp. 653-670, 2002.

[9] M. Kiuchi, J. Yanagimoto, and S. Sugiyama, "Mushy-state joining, a new process for joining materials together," in Proceedings of the 5th International Conference on Semi-Solid Processing of Alloys and Composites, pp. 123-130, Golden, Colo, USA, June 1998.

[10] P. F. Mendez, C. S. Rice, and S. B. Brown, "Joining using semisolid metals," Welding Journal, vol. 81, pp. 181-187, 2002.

[11] J. Baur, "Thixoforging of a CuZn-alloy," in Proceedings 5th International Conference on Semi-Solid Processing of Alloys and Composites, pp. 299-306, Golden, Colo, USA, 1998.

[12] M. Kiuchi, J. Yanagimoto, and S. Sugiyama, "Application of mushy/semi-solid joining," in Proceedings of the 6th International Conference on Semi-Solid Processing of Alloys and Composites, pp. 235-240, Turin, Italy, 2000.

[13] R. Baadjou, H. Shimahara, and G. Hirt, "Automated semi-solid forging of steel components by means of thixojoining," Solid State Phenomena, vol. 116-117, pp. 383-386, 2006.

[14] K. Siegert, A. Wolf, and J. Baur, "Thixoforging of aluminium and brass," in Production Engineering, vol. 1-2 of Annals of the German Academic Society for Production Engineering, pp. 21-24, 2000.

[15] H. W. Liu, C. Guo, Y. Cheng, X. F. Liu, and G. J. Shao, "Interfacial strength and structure of stainless steel-semi-solid aluminum alloy clad metal," Materials Letters, vol. 60, no. 2, pp. 180-184, 2006.

[16] H.-W. Liu and C. Guo, "Technological parameters of stainless steel-aluminum alloy semisolid joining clad," Journal of Shanghai University, vol. 11, no. 5, pp. 510-513, 2007.

[17] M. Kiuchi, J. Yanagimoto, and S. Sugiyama, "Application of mushy/semi-solid joining-part 2," in Proceedings of the 7th International Conference on Semi-Solid Processing of Alloys and Composites, pp. 707-712, Tukuba, Japan, 2002.

[18] M. Kiuchi, J. Yanagimoto, and S. Sugiyama, "Application of mushy/semi-solid joining-part 3," Journal of Materials Processing Technology, vol. 140, no. 1-3, pp. 163-166, 2003.

[19] S. Sugiyama, M. Kiuchi, and J. Yanagimoto, "Application of semisolid joining - part 4 glass/metal, plastic/metal, or wood/ metal joining," Journal of Materials Processing Technology, vol. 201, no. 1-3, pp. 623-628, 2008.

[20] R. Kopp, J. Kallweit, T. Möller, and I. Seidl, "Forming and joining of commercial steel grades in the semi-solid state," Journal of Materials Processing Technology, vol. 130-131, pp. 562$568,2002$. 
[21] G. Hirt, R. Baadjou, and F. Knauf, "Investigations on semisolid joined steel components and their bonding quality," Steel Research International, vol. 81, no. 7, pp. 589-596, 2010.

[22] R. Baadjou, F. Knauf, and G. Hirt, "Investigations on thermal influences for thixoforging and thixojoining of steel components," Solid State Phenomena, vol. 141-143, pp. 37-42, 2008.

[23] P. F. Mendez and S. B. Brown, "Method and apparatus for metal solid freeform fabrication utilizing partially solidi-fied metal slurry," United States Patent no. 5,893,404, 1999.

[24] P. F. Mendez, Joining metals using semi-solid slurries [M.S. thesis], Department of Materials Science and Engineering, Massachusetts Institute of Technology, 1995.

[25] B. S. Amirkhiz, H. Aashuri, A. Kokabi, M. A. Gharacheh, and J. Mola, "Joining metals by combining mechanical stirring and thermomechanical treatment to form a globular weld structure," Solid State Phenomena, vol. 116-117, pp. 397-401, 2006.

[26] A. Narimannezhad, H. Aashuri, A. H. Kokabi, A. Khosravani, M. Kiani, and A. Foroughi, "Semisolid joining of zinc AG40A alloy by partial remelting and mechanical stirring," Solid State Phenomena, vol. 141-143, pp. 225-230, 2008.

[27] S. M. J. Alvani, H. Aashuri, A. Kokabi, and R. Beygi, "Semisolid joining of aluminum A356 alloy by partial remelting and mechanical stirring," Transactions of Nonferrous Metals Society of China, vol. 20, no. 9, pp. 1792-1798, 2010.

[28] A. Narimannezhad, H. Aashuri, A. H. Kokabi, and A. Khosravani, "Microstructural evolution and mechanical properties of semisolid stir welded zinc AG40A die cast alloy," Journal of Materials Processing Technology, vol. 209, no. 8, pp. 4112-4121, 2009.

[29] H. B. Xu, Q. X. Luo, J. Y. He, B. F. Zhou, Y. L. Zeng, and C. H. Du, "Study of brazeability of SiCp/A356 composites and aluminum alloy using semisolid metal with high solid fraction by stirring," Advanced Materials Research, vol. 239-242, pp. 663-666, 2011.

[30] H. Xu, Q. Luo, B. Zhou, Y. Zeng, and C. Du, "The effect of stirring rate on semisolid stirring brazing of SiCp/A356 composites in air," Materials \& Design, vol. 34, pp. 452-458, 2012.

[31] H. Xu, H. Yang, Q. Luo, Y. Zeng, B. Zhou, and C. Du, "Strength and microstructure of semi-solid stirring brazing of $\mathrm{SiC}_{p} / \mathrm{A} 356$ composites and aluminum alloy in air," Advanced Materials Letters, vol. 2, no. 3, pp. 233-238, 2011.

[32] B. F. Zhou, H. B. Xu, X. Y. Ding, C. J. Zhang, and B. Dou, “The effect of the stirring with a large size of stirrer on formation of the composite joint reinforced with $\mathrm{SiC}$ particle," Applied Mechanics and Materials, vol. 300-301, pp. 1313-1316, 2013.

[33] V. A. Hosseini, H. Aashuri, and A. H. Kokabi, "Characterization of newly developed semisolid stir welding method for AZ91 magnesium alloy by using Mg-25\%Zn interlayer," Materials Science and Engineering A, vol. 565, pp. 165-171, 2013.

[34] A. Petkhwan, P. Muangjunburee, and J. Wannasin, "Investigation of microstructure and mechanical properties of semi-solid state joining of SSM aluminum alloys," Applied Mechanics and Materials, vol. 496-500, pp. 371-375, 2014.

[35] M. N. Mohammed, M. Z. Omar, M. S. Salleh, M. A. Zailani, and K. S. Alhawari, "Joining two metals via partial remelting method," Journal of Asian Scientific Research, vol. 2, pp. 724-730, 2012.

[36] M. N. Mohammed, M. Z. Omar, J. Syarif, Z. Sajuri, M. S. Salleh, and K. S. Alhawari, "Evolution of globular microstructures during direct partial re-melting experiment of AISI D2 tool steel," Applied Mechanics and Materials, vol. 465-466, pp. 829833, 2014.
[37] M. N. Mohammed, M. Z. Omar, M. S. Salleh, K. S. Alhawari, and P. Kapranos, "Semisolid metal processing techniques for nondendritic feedstock production," The Scientific World Journal, vol. 2013, Article ID 752175, 16 pages, 2013.

[38] M. N. Mohammed, M. Z. Omar, J. Syarif, Z. Sajuri, M. S. Salleh, and K. S. Alhawari, "Semi-solid joining of D2 cold-work tool steel," in Proceedings of the 13th International Conference on Semi-Solid Processing of Alloys and Composites, Muscat, Oman, 2014.

[39] M. N. Mohammed, M. Z. Omar, J. Syarif, Z. Sajuri, M. S. Salleh, and K. S. Alhawari, "Microstructural properties of semisolid welded joints for AISI D2 tool steel," Jurnal Kejuruteraan, vol. 26, pp. 31-34, 2014.

[40] M. N. Mohammed, M. Z. Omar, M. S. Salleh, and K. S. Alhawari, "Study on thixojoining process using partial remelting method," Advances in Materials Science and Engineering, vol. 2013, Article ID 251472, 8 pages, 2013.

[41] A. Kalaki, M. Ketabchi, and S. Zangeneh, "Fracture surface analysis in thixojoined tool steels," ISRN Materials Science, vol. 2014, Article ID 489487, 5 pages, 2014.

[42] A. Kalaki, M. Ketabchi, and M. Abbasi, "Thixo-joining of D2 and M2 tool steels: analysis of microstructure and mechanical properties," International Journal of Materials Research, vol. 105, no. 8, pp. 764-769, 2014.

[43] H. Xu, B. Zhou, C. Du, Q. Luo, and H. Chen, "Microstructure and properties of joint interface of semisolid stirring brazing of composites," Journal of Materials Science \& Technology, vol. 28, no. 12, pp. 1163-1168, 2012.

[44] M. N. Mohammed, M. Z. Omar, J. Syarif, Z. Sajuri, M. S. Salleh, and K. S. Alhawari, "Microstructural evolution during DPRM process of semisolid ledeburitic D2 tool steel," The Scientific World Journal, vol. 2013, Article ID 828926, 7 pages, 2013.

[45] M. N. Mohammed, M. Z. Omar, M. S. Salleh, K. S. Alhawari, and M. A. Abdelgnei, "An overview of semi-solid metal processing," Australian Journal of Basic and Applied Sciences, vol. 8, no. 19, pp. 369-373, 2014. 

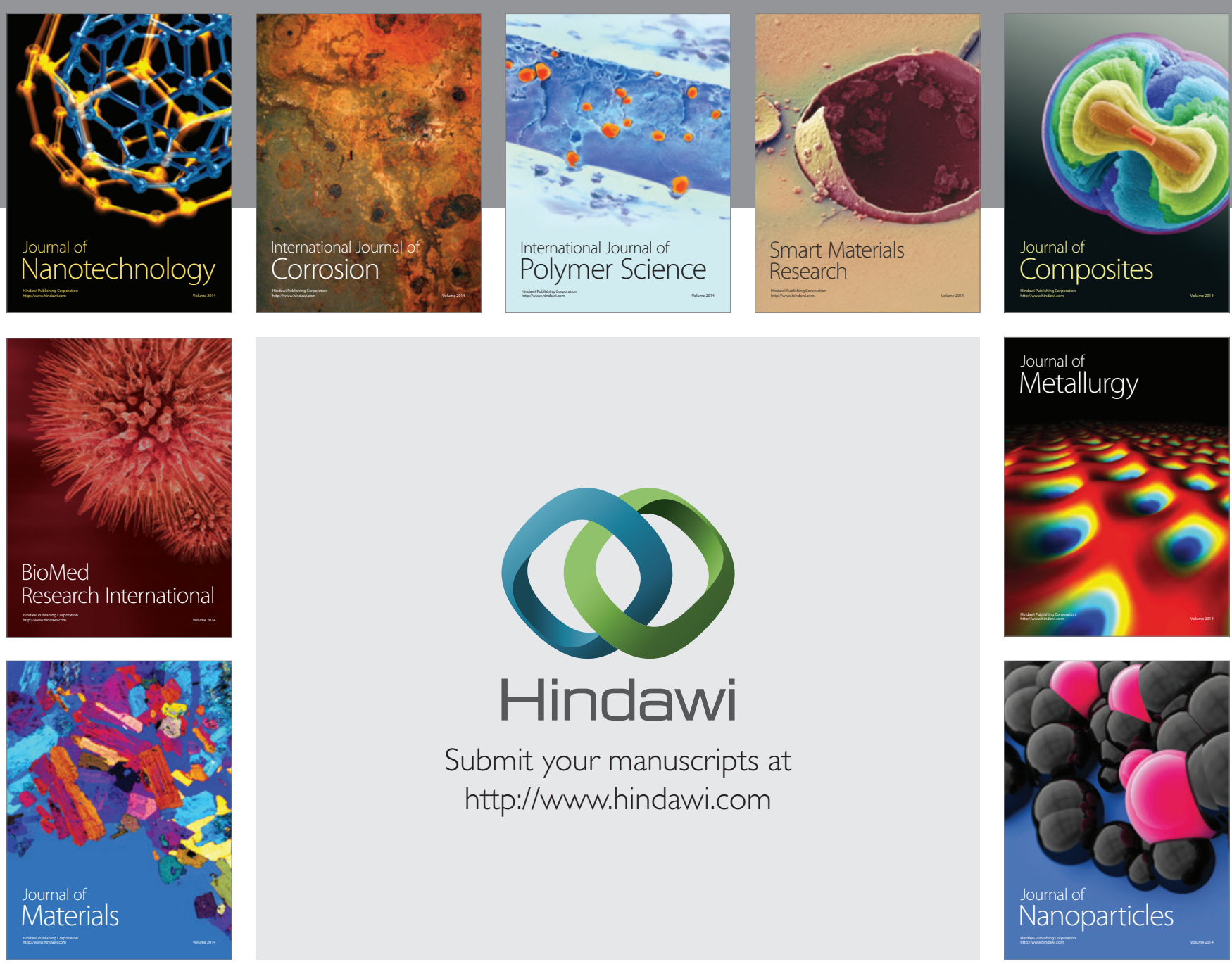

Submit your manuscripts at http://www.hindawi.com
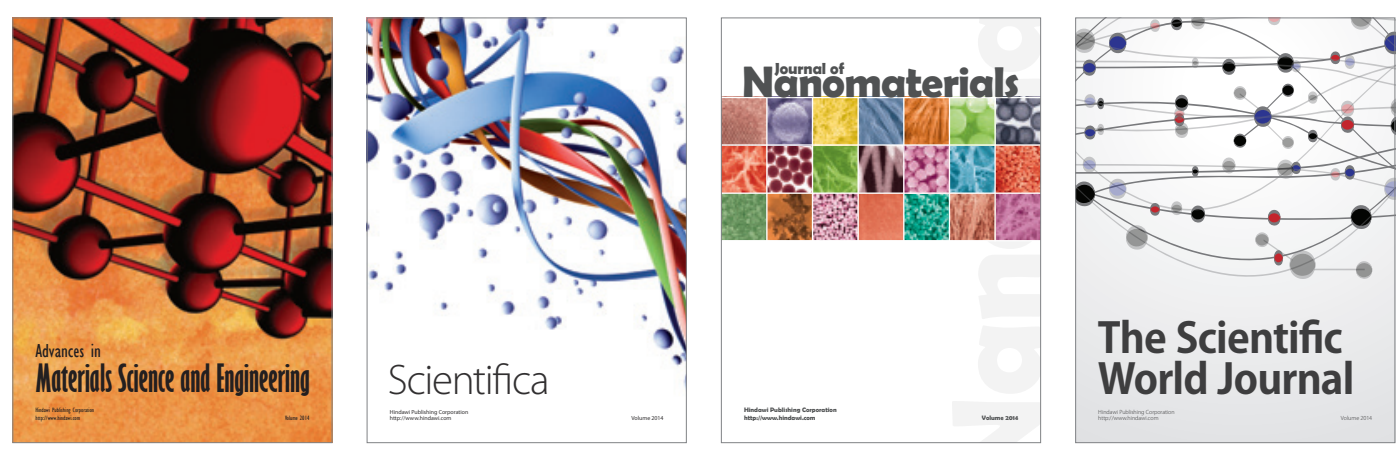

\section{The Scientific World Journal}
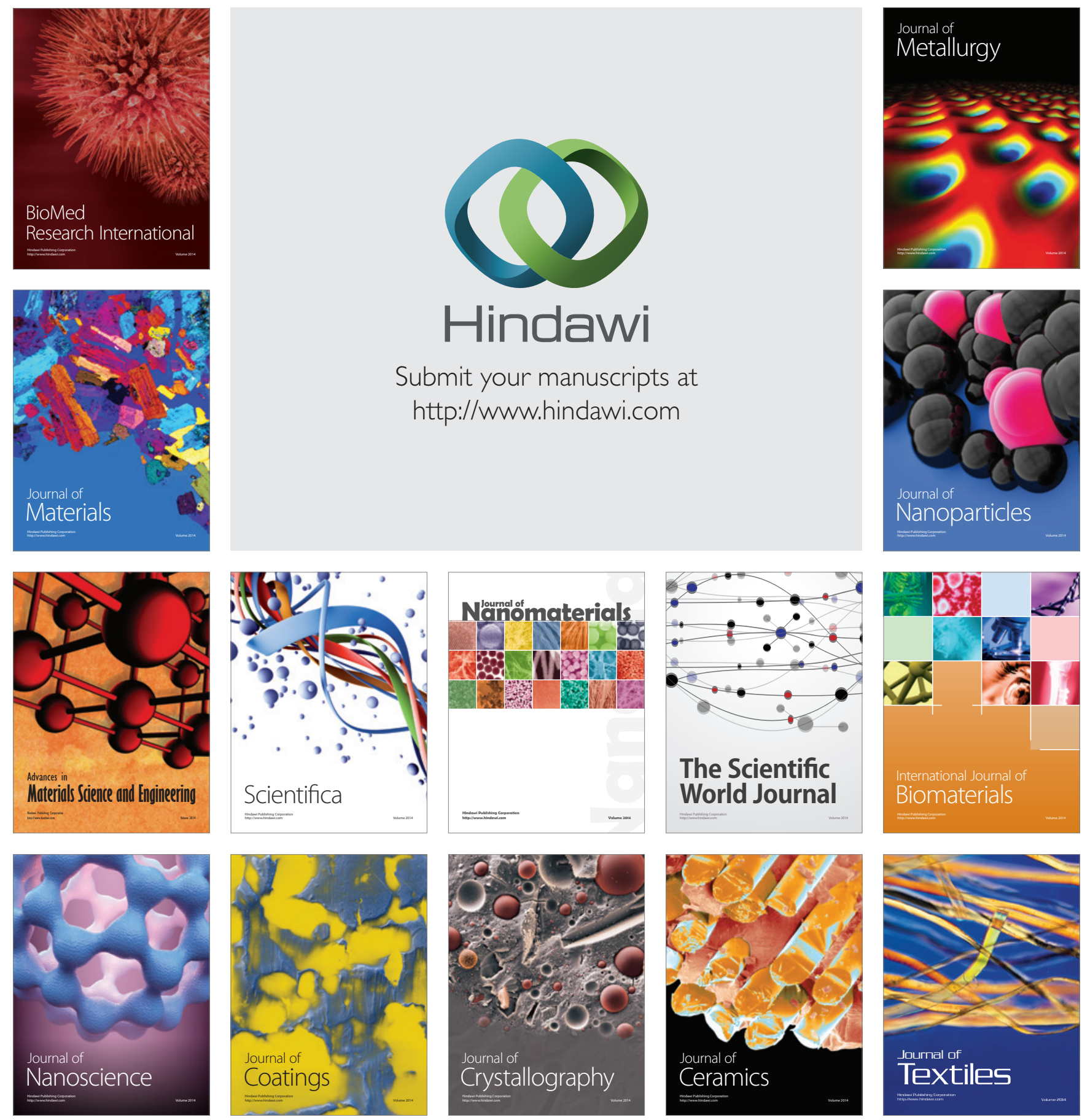